\title{
A Cysteine Protease Gene Is Expressed Early in Resistant Potato Interactions with Phytophthora infestans
}

\author{
Anna O. Avrova, Helen E. Stewart, Walter De Jong, Jacqueline Heilbronn, Gary D. Lyon, \\ and Paul R. J. Birch \\ Departments of Fungal and Bacterial Plant Pathology and of Crop Genetics, Scottish Crop Research \\ Institute (SCRI), Invergowrie, Dundee, DD2 5DA, U.K. \\ Accepted 3 September 1999.
}

A potato cysteine protease (cyp) cDNA expressed at an early stage of an incompatible interaction with Phytophthora infestans was isolated. Both the nucleotide and deduced amino acid sequences are highly homologous to those of a tomato cysteine protease, CYP1. Striking protein similarity to all known cathepsins in animals, particularly cathepsin $K$, was also observed. However, unlike cathepsins, a granulin binding domain is located near the carboxyl terminus of the putative CYP protein. In animals, granulins bind to receptors in the plasma membrane and signal cell growth and division. A ribonuclease protection assay demonstrated that the cyp gene is tightly regulated and is induced $15 \mathrm{~h}$ post inoculation with $P$. infestans in potato leaves either with high field resistance or in which a resistance $(R)$ gene is activated. We conclude that a common signaling pathway is activated in each form of resistance.

Additional keywords: hypersensitive response, programmed cell death.

In recent years, evidence has suggested that many plant processes, including development, reproduction, xylogenesis, and senescence, involve programmed cell death (PCD) similar to apoptosis in animals (Greenberg 1996; Beers 1997). Moreover, PCD in plants occurs in response to pathogen attack, most demonstrably in the hypersensitive response (HR) that characterizes an "incompatible" interaction. Morphological features of apoptosis, such as membrane blebbing, chromatin condensation, and DNA fragmentation, can be observed in at least some examples of the HR (Pontier et al. 1998; Heath 1998). Pathogen recognition in plants may be mediated by receptors with domains that are similar to those found in pro-apoptotic adaptor proteins in animals (van der Biezen and Jones 1998), and signaling/signal transduction in both the HR and apoptosis involve

Corresponding author: Paul R. J. Birch; Telephone: +44 1382 562731; Fax: +44 1382 562426; E-mail: pbirch@ scri.sari.ac.uk

Nucleotide and/or amino acid sequence data can be found at the EMBL data base as accession no. AJ245924. changes in protein phosphorylation, ion fluxes, and reactive oxygen species, and may involve lipid-based second messengers (Gilchrist 1997; Pontier et al. 1998).

Central to apoptosis in animal cells is the tightly regulated proteolytic cleavage of a limited number of cellular proteins. The main enzymes involved in this process are caspases, aspartate-specific cysteine proteases, although other cysteine proteases such as calpains and cathepsins, serine proteases such as granzymes, and the proteasome-ubiquitin pathway are all reported to be involved in apoptosis (reviewed in Solary et al. 1998). Cysteine protease genes have been shown to be up-regulated in plant PCD processes such as development (Xu and Chye 1999) and senescence (Drake et al. 1996; Kardailsky and Brewin 1996; Griffiths et al. 1997; Guerrero et al. 1998). Furthermore, cysteine protease activities appear to be involved in the HR (del Pozo and Lam 1998; D'Silva et al. 1998; Solomon et al. 1999). Nevertheless, caspase activity in these PCD processes remains to be conclusively proven. del Pozo and Lam (1998) reported cleavage of a short oligopeptide at the aspartate residue during infection of resistant tobacco by tobacco mosaic virus. However, with a longer synthetic peptide, no such activity was seen from soybean cysteine proteases purified from cells undergoing PCD in response to oxidative stress (Solomon et al. 1999). D'Silva et al. (1998) demonstrated the cleavage of poly (ADP-ribose) polymerase (PARP) by cysteine proteases activated during the HR of cowpea to cowpea rust fungus. PARP is normally a target for cleavage by caspases during apoptosis in animals (reviewed in Vaux and Korsemeyer 1999). Inhibition of cysteine proteases with cystatin blocked PCD in soybean triggered by either oxidative stress or an avirulent strain of Pseudomonas syringae pv. glycinea (Solomon et al. 1999). Both Solomon et al. (1999) and D'Silva et al. (1998) have suggested a regulatory role for cysteine proteases and their inhibitors during the HR in plants. As yet, the genes encoding these HR-associated cysteine proteases have not been isolated.

Recently, we reported the generation of a cDNA library enriched for potato sequences up-regulated at an early stage of an incompatible interaction with Phytophthora infestans (Birch et al. 1999). This library was generated by suppression 
subtractive hybridization ( $\mathrm{SSH}$ ) of cDNA from leaves of resistant cv. Stirling (the "tester" cDNA population), $24 \mathrm{~h}$ post inoculation with an avirulent isolate of $P$. infestans, with cDNA from infected leaves of susceptible cv. Bintje as a driver. Sequence analysis of the library revealed two clones containing contiguous cDNA fragments that matched a number of cysteine proteases (Birch et al. 1999). Here, we describe the isolation of a full-length potato cyp cDNA, and demonstrate that it is up-regulated early in resistance responses to $P$. infestans.

To obtain a full-length cDNA sequence of the gene, cDNA of cv. Stirling $15 \mathrm{~h}$ after inoculation with an incompatible race of $P$. infestans was used as a template for $3^{\prime}$ and $5^{\prime}$ RACE (rapid amplification of cDNA ends; Marathon cDNA Amplification Kit, protocol PT1115-1; Clontech, Palo Alto, Ca). The cDNA was synthesized from RNA extracted with an RNeasy Plant minikit (Qiagen, Hilden, Germany). Double-stranded cDNA was synthesized with the First-Strand cDNA Synthesis Kit (Amersham Pharmacia Biotech, Little Chalfont, UK) and the Riboclone cDNA Synthesis System (Promega, Madison, WI). Specific primers used for $3^{\prime}$ and $5^{\prime}$ RACE and for sequencing are given in Table 1. Amplification products were purified with the Promega Wizard PCR Preps kit, cloned with the Promega pGEM-T vector cloning kit, and transformed into Ultracompetent Epicurian coli XL2-blue MRF' cells (Stratagene, La Jolla, CA). Plasmid preparations (Qiagen Plasmid Miniprep kit) of clones derived from each amplification product were sequenced (ABI PRISM Dye Terminator cycle sequencing kit and ABI Model 377 DNA sequencer; Perkin Elmer, Warrington, U.K.) in both directions (with Promega M13 forward and reverse or with gene-specific primers; Table 1). In parallel to this work, a full-length cDNA matching the cysteine protease was independently identified at SCRI by random sequencing of a cDNA library from a doubled $(2 \mathrm{n}=2 \mathrm{x})$ potato monoploid $(851-5)$, cloned into pSPORT1 with the SuperScript plasmid system (GibcoBRL, Paisley, Scotland).

The complete cDNA sequence of cyp (EMBL accession number AJ245924) reveals an open reading frame encoding a putative polypeptide of 466 amino acids, with a molecular mass of approximately $50 \mathrm{kDa}$ (Fig. 1). Both the DNA and deduced amino acid sequences show high levels of homology (93.7 and $95.7 \%$, respectively) to a tomato cysteine protease, CYP1 (accession no. AJ003137), and are also similar to gibberellin-induced oryzain $\alpha$ (accession no. D90406). Furthermore, the predicted amino acid sequence shows strong homology to all known cathepsins in animals, particularly cathepsin K (accession no. P43235) (Fig. 1). Two domains can be identified in the protein: a cysteine protease domain, pres-

Table 1. Oligonucleotide primers used for $3^{\prime}$ and $5^{\prime}$ RACE (rapid amplification cDNA ends) and for sequencing

\begin{tabular}{llc}
\hline $\begin{array}{l}\text { Primer } \\
\text { name }\end{array}$ & Sequence & $\begin{array}{c}\text { Annealing } \\
\text { temp. }\end{array}$ \\
\hline CYPR1 & 5'-CAATAGGCTGTGCAAGAATGCG-3' & $65^{\circ} \mathrm{C}$ \\
CYPR3 & 5'-ATAAGTCGTACAATGAAGGTTGC-3' & $65^{\circ} \mathrm{C}$ \\
CYPR4 & 5'-CAAAGGCGTAGTCCATAAGACC-3' & $62^{\circ} \mathrm{C}$ \\
CYPF1 & 5'-GCAGCTCACAGCTCAACTCTC-3' & $62^{\circ} \mathrm{C}$ \\
149RT1 & 5'-CAGCAGAAAGGTGTAGAGACAG-3' & $64^{\circ} \mathrm{C}$ \\
149RT2 & 5'-TGAAGAAGGACTATTGTTCTAC-3' & $60^{\circ} \mathrm{C}$ \\
149D & 5'-CTGTCTCTACACCTTTCTGCTG-3' & $64^{\circ} \mathrm{C}$ \\
\hline
\end{tabular}

ent in all plant and mammalian cysteine proteases, and also a C-terminal, granulinlike domain (Fig. 1). Detailed comparison of the cysteine protease domains between the potato CYP, tomato CYP1, rice oryzain $\alpha$, and cathepsin $K$ reveals that amino acids critical to the structure and function of cysteine proteases are conserved in all of them. Specifically, the catalytic cysteine-histidine-asparagine triad, Cys162, His298, Asn318 (Fig. 1, open circles) and cysteines forming disulfide bridges, Cys159-Cys201, Cys193-Cys234 and Cys292Cys343 (Fig. 1, marked \#) are conserved.

The granulin domain appears to be highly conserved among several plant cysteine proteases, including CYP1 and thiol protease C14 (accession no. M21444) from tomato, oryzain $\alpha$ and $\beta$ (accession no. D90407) from rice, RD21A (accession no. P43297) from Arabidopsis thaliana, CP3 (accession no. Z99954) from Phaseolus vulgaris, thiol protease (accession no. X66061) from pea, and Mir3 (accession no. AF019147) from maize (Fig. 2). Other plant cysteine proteases, including CYS4 (accession no. P25251) from Brassica napus, See1 (accession no. X99936) and Ccp2 (accession no. D45403) from maize, aleurain (accession no. P05167), CYSP (accession no. P43156), EPB1 (accession no. U19359), and EPB2 (accession no. U19384) from barley, oryzain $\gamma$ (accession no. D90408) from rice, papains (e.g., accession nos. P00784, X97789, X78056, X69877) and mammalian cathepsins (e.g., accession nos. M90696, P43235, P07711, P09668, P07858), lack such a domain.

Granulins are a family of evolutionarily ancient proteins that are involved in regulating cell growth in animals (Bateman and Bennett 1998). Antisense expression of granulin in a cancerous animal cell line results in inhibition of tumorigenicity, suggesting a role for granulins in stimulating cell division (Zhang and Serrero 1998). They are structurally organized as multiple repeats of the cysteine-rich module shown in Figure 2 (Trinh et al. 1999) and have been shown to bind to a specific cell surface receptor in animals (Xia and Serrero 1998). The presence of a granulin domain at the $\mathrm{C}$ terminus of the putative potato CYP protein raises the possibility of such receptors in plants. If they exist, and they have a role in promoting cell growth, binding a cysteine protease to such receptors may lead to their inactivation, and to the consequent activation of a cell death pathway. If this is so, one might expect the cyp gene to be up-regulated at an early stage of hypersensitive cell death in response to pathogen attack. In addition, one would expect CYP to be secreted into the apoplast. A classic hydrophobic leader sequence (amino acids 1 to 24) and a signal peptide cleavage site between amino acids 24 and 25 (according to Nielsen et al. 1997) suggest that CYP may indeed be a secreted protein.

To assess the transcriptional regulation of the cyp gene we performed ribonuclease protection assays (RPA II Kit, 108K0438; Ambion, Austin, TX) with RNAs isolated from different time points $(15,48$, and $72 \mathrm{~h})$ after inoculation of a variety of potato cultivars with $P$. infestans. To allow for variation in response, five glasshouse-grown plants of each cultivar were sprayed with a suspension of zoospores $\left(5 \times 10^{4}\right.$ per ml), as described by Stewart et al. (1983), and leaf material pooled prior to RNA extraction. In each case, RNAs from uninfected leaves were prepared as controls. Chosen were cv. Bintje, which is free of resistance $(R)$ genes and which has a field resistance rating of only 2 according to the International 


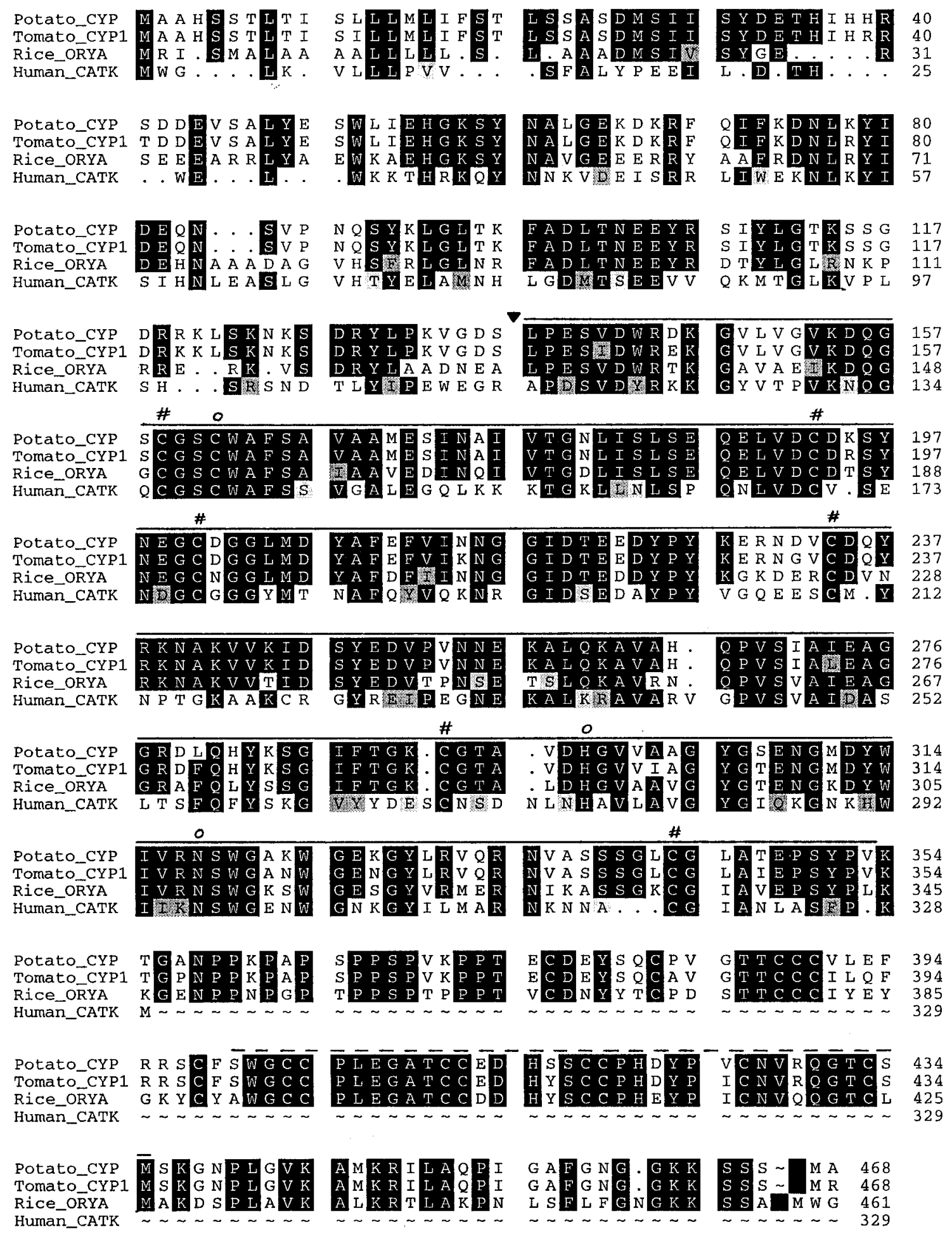

Fig. 1. Amino acid sequence alignment of the predicted potato CYP polypeptide with sequences of cysteine proteases from tomato (accession no. AJ003137), rice (accession no. D90406), and human cathepsin K (accession no. P43235). Likely site of cleavage to generate the mature protein is indicated with solid triangle. Solid black line indicates cys-protease domain; dashed line indicates granulin domain. Catalytic cysteine-histidine-asparagine triad is marked with open circles; cysteines forming disulfide bridges are marked \#. Proteins were aligned with PILEUP and LINEUP (Wisconsin Genetics Computer Group software package), and are displayed with the use of PRETTYBOX. Black shading shows identical amino acids; gray shading indicates conserved substitutions. 
1-9 scale (NIAB 1999), cv. Stirling, with high field resistance (rating 8; NIAB 1999) and an uncharacterized $R$ gene (Milbourne 1999), and two genotypes of Black's differential series (Black et al. 1953), Pentland Ace and 1512 c (16) (containing the $R 3$ and $R 2$ genes, respectively) that, when included in SCRI field trials of breeder lines, have been allocated a field resistance rating of 2 (averaged over 10 years; H. E. Stewart, unpublished data). In all cases, $P$. infestans inoculations were made with either a race 1,4 isolate, which gave a clear incompatible interaction with Stirling, Pentland Ace, and 1512 c (16), or with a race 1,2,3,4,6,7 isolate, which gave a compatible interaction with Pentland Ace and $1512 \mathrm{c}$ (16) and very slowly developing lesions with Stirling. The races had been isolated from potato crops in Scotland during the previous growing season, and maintained on RyeA agar over winter and on detached potato leaflets prior to use. Both races gave a clear compatible interaction with Bintje. Additional plants (inoculated and uninoculated) kept as controls for 5 days after inoculation showed similar levels of infection on Bintje, but a clear difference between Stirling plants inoculated with the different races (results not shown).

For the ribonuclease protection assay, probes were prepared with a clone containing $148 \mathrm{bp}$ of the $3^{\prime}$ untranslated region (UTR) of the cyp gene (clone STLB2; Birch et al. 1999) and a fragment of potato $25 \mathrm{~S}$ rRNA as a control. Riboprobes were made with the Promega Riboprobe Combination SP6/T7 system, as specified by the manufacturer. The results of the analysis are shown in Figure 3. Those for Pentland Ace and 1512 c (16) were identical, so only the former are included in the figure. In all cases, the rRNA probe revealed similar levels of RNA from each cultivar, each interaction and each time point after inoculation (Fig. 3).

Only low-level expression of the cyp gene could be detected in any uninfected cultivar, or in infected Bintje, or Pentland Ace and 1512 c (16) compatible interactions. However, a strong hybridization signal was observed specifically at the 15-h time points in incompatible interactions for Pentland Ace, 1512 c (16), and Stirling (Fig. 3). Interestingly, a similar pattern of cyp up-regulation was observed at the 15-h time point in the so-called "compatible" interaction between Stirling and $P$. infestans (Fig. 3C, lane 2). Lesions only slowly develop in this interaction, as there are appreciable levels of foliar blight resistance. This suggests that a common signaling pathway, leading to the expression of cyp, is being activated in each of these resistance responses. In a recent review, Kamoun et al. (1999) suggest that resistance responses to oomycetes, whether $R$ gene mediated or quantitative (field), invariably involve the HR. If this is so, then the cyp gene may be a marker for hypersensitive cell death.

Previous microscopic analyses of compatible and incompatible interactions between potato cv. Datura and $P$. infestans have revealed little difference in rate of hyphal growth before 12 to 14 h post inoculation (Cuypers and Hahlbrock 1988). By this stage, these authors reported, hyphae had penetrated to the boundary between palisade parenchyma and upper epidermis, and a clear differential response in surrounding potato cells was observed; in the compatible interaction few cells showed a visible response, whereas parenchyma cells responded with rapid browning in the incompatible interaction. By $24 \mathrm{~h}$, the color intensity and area of necrotic tissue had reached a maximum in the incompatible interaction. In contrast, $24 \mathrm{~h}$ post inoculation in the compatible interaction the hyphae had penetrated the upper epidermis and started to sporulate (Cuypers and Hahlbrock 1988). Given the different cultivars and $P$. infestans isolates used in this study, the up-regulation of cyp at $15 \mathrm{~h}$ nevertheless correlates well with the onset of phenotypic differences observed previously under the microscope between compatible and incompatible interactions.

As stated above, cysteine protease activity is involved in a number of PCD processes in animals and plants, including the plant HR (del Pozo and Lam 1998; D’Silva et al. 1998; Birch et al. 1999; Solomon et al. 1999). In animals, the caspases,
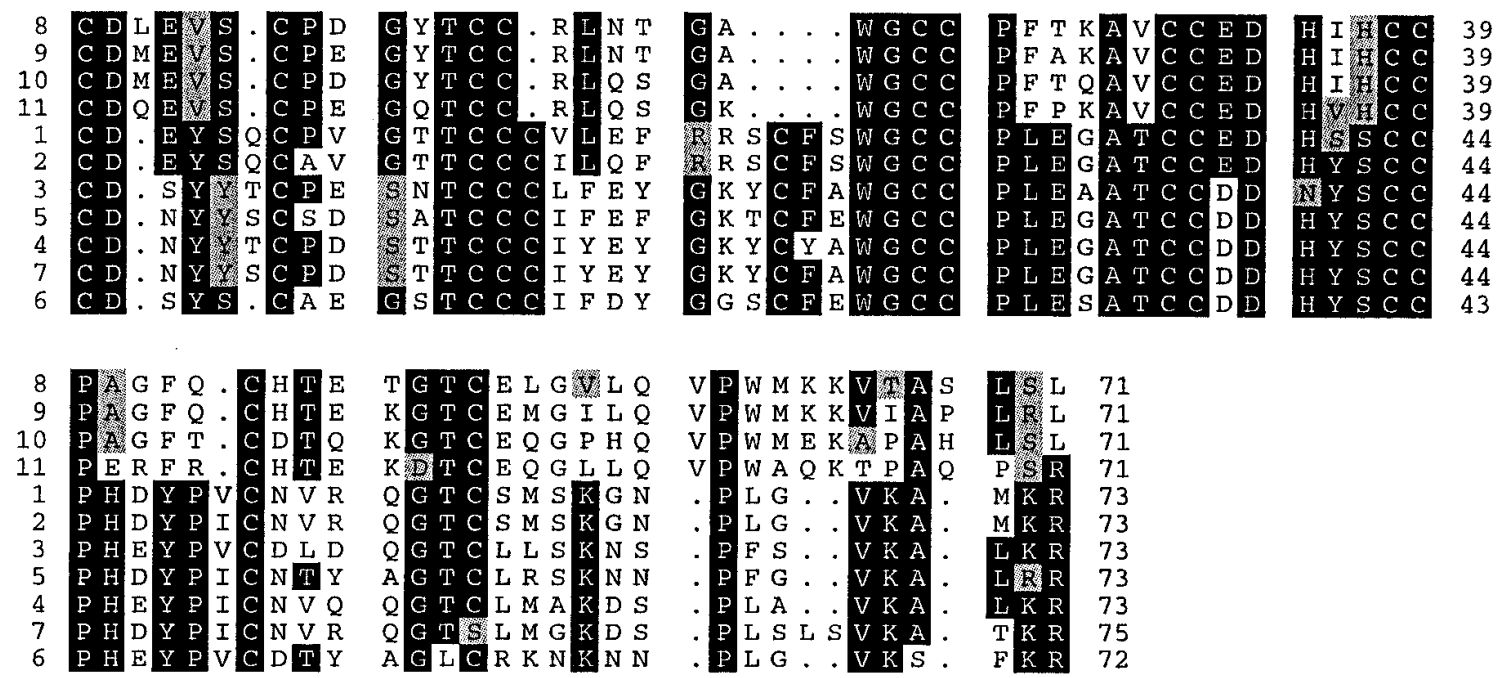

Fig. 2. Sequence alignment of the granulin domains of potato CYP (1), tomato CYP1 (2) (accession no. AJ003137), Arabidopsis RD21A (3) (accession no. P43297), rice ORYA (4) (accession no. D90406), Phaseolus vulgaris CP3 (5) (accession no. Z99954), pea thiolprotease (6) (accession no. X66061), and maize Mir3 (7) (accession no. AF019147) with sequences of granulins from rat (8) (accession no. P23785), mouse (9) (accession no. P28798), human (10) (accession no. P28799), and guinea pig (11) (accession no. P28797). Proteins were aligned in order of relatedness with PILEUP and LINEUP (Wisconsin Genetics Computer Group software package), and are displayed with the use of PRETTYBOX. Black shading shows identical amino acids; gray shading indicates conserved substitutions. 


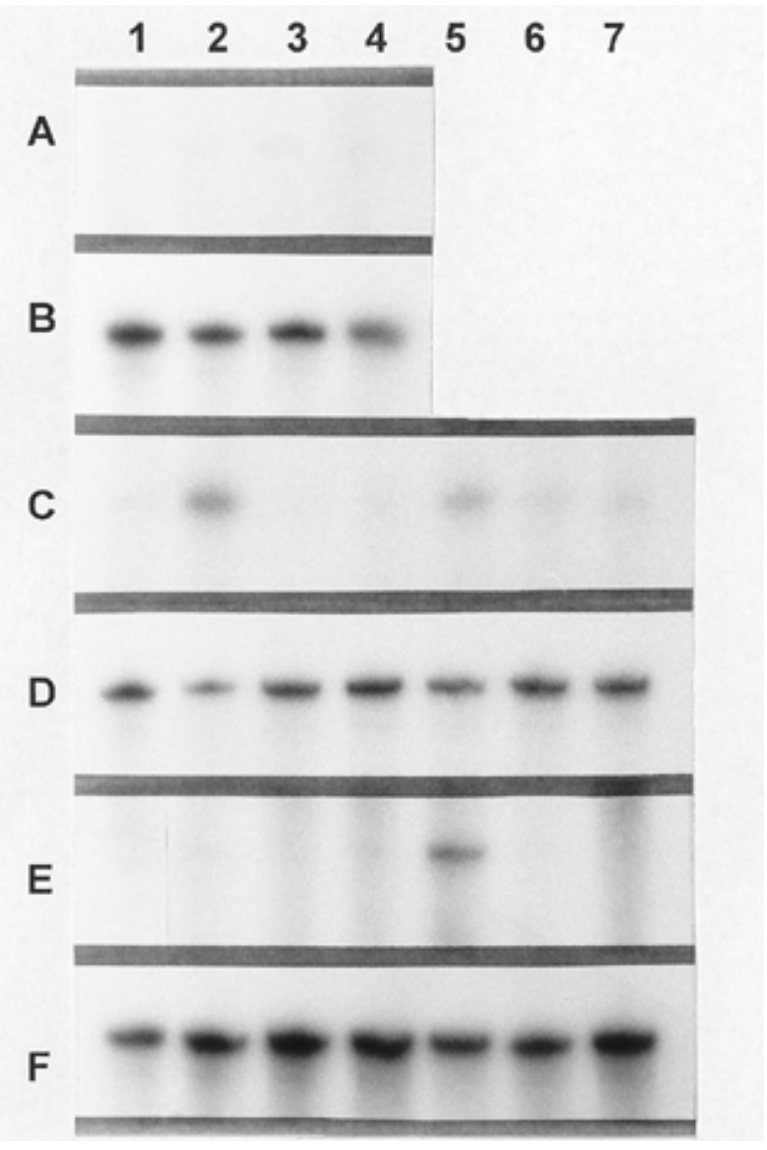

Fig. 3. Ribonuclease protection assay with RNA from leaves of potato cvs. (A and B) Bintje, (C and D) Stirling, and (E and $\mathbf{F})$ Pentland Ace. In each panel RNA is from uninfected plant (lane 1), from plant 15, 48, and $72 \mathrm{~h}$ after inoculation with a compatible race of $P$. infestans (lanes $2-4$, respectively), and 15,48 , and $72 \mathrm{~h}$ after inoculation with an incompatible race of $P$. infestans (lanes 5-7, respectively). ${ }^{32} \mathrm{P}$-labeled riboprobe corresponding to the $3^{\prime}$ UTR of the cysteine protease (clone STLB2; Birch et al. 1999) (A, C, E) was, in each case, hybridized to 30 $\mu \mathrm{g}$ of total RNA, and ${ }^{32} \mathrm{P}$-labeled riboprobe corresponding to a fragment of potato $25 \mathrm{~S}$ rRNA $(\mathbf{B}, \mathbf{D}, \mathbf{F})$ was hybridized, in each case, to $10 \mu \mathrm{g}$ of total RNA.

which are the main effectors of apoptosis, may be activated by adaptors, such as Apaf1, or by other, regulatory, caspases (e.g., Vaux and Korsmeyer 1999). In addition, cathepsin B has been shown to activate caspases (Vancompernolle et al. 1998). It is thus intriguing that the cyp gene encodes a cathepsin-like cysteine protease. It will be interesting to discover whether this protease possesses caspaselike regulatory functions by activating and inactivating proteins, and whether the granulin binding domain is involved in directing this activity to specific protein targets.

\section{ACKNOWLEDGMENTS}

This work was funded by the Scottish Office Agriculture, Environment and Fisheries Department. A. O. A. was funded by a NATO-Royal Society grant.

\section{LITERATURE CITED}

Bateman, A., and Bennett, H. P. 1998. Granulins: The structure and function of an emerging family of growth factors. J. Endocrinol. 158:
145-151.

Beers, E. P. 1997. Programmed cell death during plant growth and development. Cell Death Differ. 4:649-661.

Birch, P. R. J., Avrova, A. O., Duncan, J. M., Lyon, G. D., and Toth, R. L. 1999. Isolation of potato genes that are induced during an early stage of the hypersensitive response to Phytophthora infestans. Mol. Plant-Microbe Interact. 12:356-361.

Black, W., Mastenbroek, C., Mills, W. R., and Peterson, L. C. 1953. A proposal for an international nomenclature of races of Phytophthora infestans and of genes controlling immunity in Solanum demissum derivatives. Euphytica 2:173-178.

Cuypers, B., and Hahlbrock, K. 1988. Imunohistochemical studies of compatible and incompatible interactions of potato leaves with Phytophthora infestans and of the nonhost response to Phytophthora megasperma. Can. J. Bot. 66:700-705.

del Pozo, O., and Lam, E. 1998. Caspases and programmed cell death in the hypersensitive response of plants to pathogens. Curr. Biol. 8:112932.

Drake, R., John, I., Farrell, A., Cooper, W., Schuch, W., and Grierson, D. 1996. Isolation and analysis of cDNA encoding tomato cysteine proteases expressed during leaf senescence. Plant Mol. Biol. 30:755-767.

D'Silva, I., Poirier, G. G., and Heath, M. C. 1998. Activation of cysteine proteases in cowpea plants during the hypersensitive response - a form of programmed cell death. Exp. Cell Res. 245:389-399.

Gilchrist, D. G. 1997. Mycotoxins reveal connections between plants and animals in apoptosis and ceramide signaling. Cell Death Differ. 4: 689-698.

Greenberg, J. T. 1996. Programmed cell death: A way of life for plants. Proc. Natl. Acad. Sci. USA 93:12094-12097.

Griffiths, C. M., Hosken, S. E., Oliver, D., Chojeski, J., and Thomas, H. 1997. Sequencing, expression pattern and RFLP mapping of a senescent-enhanced cDNA from Zea mays with high homology to oryzain $\gamma$ and aleurain. Plant Mol. Biol. 34:815-821.

Guerrero, C., de la Calle, M., Reid, M. S., and Valpuesta, V. 1998. Analysis of the expression of two thiolprotease genes from daylily (Hemerocalis spp.) during flower senescence. Plant Mol. Biol. 36: 565-571.

Heath, M. C. 1998. Apoptosis, programmed cell death and the hypersensitive response. Eur. J. Plant Pathol. 104:117-124.

Kamoun, S., Huitema, E., and Vleeshouwers, V.G. 1999. Resistance to oomycetes: A general role for the hypersensitive response? Trends Plant. Sci. 4:196-200.

Kardailsky, I. V., and Brewin, N. J. 1996. Expression of cysteine protease genes in pea nodule development and senescence. Mol. PlantMicrobe Interact. 9:689-695.

Milbourne, D. 1999. Development and assessment of tools and strategies for linkage and QTL analysis in tetraploid potato. Ph.D. thesis. University of Dundee, Dundee, UK.

National Institute of Agricultural Botany (NIAB). 1999. Potato variety handbook 2000. Recommended list of potatoes. E \& E Plumridge, Linton, Cambridge.

Nielsen, H., Engelbrecht, J., Brunak, S., and von Heijne, G. 1997. Identification of prokaryotic and eukaryotic signal peptides and prediction of their cleavage sites. Pro. Eng. 10:1-6.

Pontier, D., Balague, C., and Roby, D. 1998. The hypersensitive response: A programmed cell death associated with plant resistance. C.R. Acad. Sci. III 321:721-734.

Solary, E., Eymin, B., Droin, N., and Haugg, M. 1998. Proteases, proteolysis, and apoptosis. Cell Biol. Toxicol. 14:121-132.

Solomon, M., Belenghi, B., Delledone, M., Menachen, E., and Levine, A. 1999. The involvement of cysteine proteases and protease inhibitor genes in the regulation of programmed cell death in plants. Plant Cell 11:431-443.

Stewart, H. E., Flavelle, P. H., McCalmont, D. C., and Wastie, R. L. 1983. Correlation between glasshouse and field tests for resistance to foliage blight caused by Phytophthora infestans. Potato Res. 26:4148.

Trinh, D. P., Brown, K. M., and Jeang, K. T. 1999. Epithelin/granulin growth factors: Extracellular cofactors for HIV-1 and HIV-2 Tat proteins. Biochem. Biophys. Res. Commun. 256:299-306.

van der Biezen, E. A., and Jones, J. D. G. 1998. The NB-ARC domain: A novel signalling motif shared by plant resistance gene products and regulators of cell death in animals. Curr. Biol. 8:226-227.

Vancompernolle, K., Van Herreweghe, F., Pynaert, G., Van de Craen, M., 
De Vos, K., Totty, N., and Sterling, A. 1998. Atractyloside-induced release of cathepsin $\mathrm{B}$, a protease with caspase-processing activity. FEBS Lett. 438:150-158.

Vaux, D. L., and Korsmeyer, S. J. 1999. Cell death in development. Cell 96:245-254

Xia, X., and Serrero, G. 1998. Identification of cell surface binding sites for PC-cell-derived growth factor, PCDGF, (epithelin/granulin precursor) on epithelial cells and fibroblasts. Biochem. Biophys. Res. Com- mun. 245:539-543.

Xu, F.-X., and Chye, M.-L. 1999. Expression of cysteine protease during developmental events associated with programmed cell death in brinjal. Plant J. 17:321-327.

Zhang, H., and Serrero, G. 1998. Inhibition of tumorigenicity of the teratoma PC cell line by transfection with antisense cDNA for PC cell-derived growth factor (PCDGF, epithelin/granulin precursor). Proc. Natl. Acad. Sci. USA 5:14202-14207. 